\title{
Disruption of the pleiotropic gene scoC causes transcriptomic and phenotypical changes in Bacillus pumilus BA06
}

\author{
Lin-Li Han, Yong-Cheng Liu, Cui-Cui Miao and Hong Feng ${ }^{*}$ (i)
}

\begin{abstract}
Background: Bacillus pumilus is a Gram-positive and endospore-forming bacterium broadly existing in a variety of environmental niches. Because it produces and secrets many industrially useful enzymes, a lot of studies have been done to understand the underlying mechanisms. Among them, scoC was originally identified as a pleiotropic transcription factor negatively regulating protease production and sporulation in B. subtilis. Nevertheless, its role in B. pumilus largely remains unknown.
\end{abstract}

Results: In this study we successfully disrupted scoC gene in B. pumilus BA06 and found increased total extracellular protease activity in $s c 0 C$ mutant strain. Surprisingly, we also found that scoC disruption reduced cell motility possibly by affecting flagella formation. To better understand the underlying mechanism, we performed transcriptome analysis with RNA sequencing. The result showed that more than one thousand genes were alternated at transcriptional level across multiple growth phases, and among them the largest number of differentially expressed genes (DEGs) were identified at the transition time point $(12 \mathrm{~h}$ ) between the exponential growth and the stationary growth phases. In accordance with the altered phenotype, many protease genes especially the aprE gene encoding alkaline protease were transcriptionally regulated. In contrast to the finding in B. subtilis, the aprN gene encoding neutral protease was transcriptionally downregulated in B. pumilus, implicating that scoC plays strain-specific roles.

Conclusions: The pleiotropic transcription factor ScoC plays multiple roles in various cellular processes in B. pumilus, some of which were previously reported in B. subtilis. The supervising finding is the identification of ScoC as a positive regulator for flagella formation and bacterial motility. Our transcriptome data may provide hints to understand the underlying mechanism.

Keywords: Bacillus pumilus, Flagella, Motility, Protease, scoC, Transcriptome

\section{Background}

Bacillus pumilus is a Gram-positive bacterium with great potential for industrial applications. It produces and secretes a variety of useful enzymes [1-5]. It has also been developed as bio-pesticide or bio-fertilizer [6, 7]. Moreover, because of its favorable growth and secretion features, B. pumilus has been engineered as host organism for recombinant protein production [8-10].

Previously, we isolated a $B$. pumilus strain named BA06 for its high level production of extracellular

\footnotetext{
* Correspondence: hfeng@scu.edu.cn

Key Laboratory for Bio-resources and Eco-Environment of the Ministry of Education, Sichuan Key Laboratory of Molecular Biology and Biotechnology, College of Life Sciences, Sichuan University, Chengdu, People's Republic of China
}

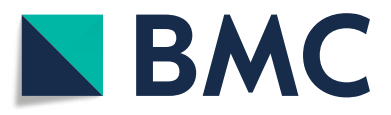

(๑) The Author(s). 2019 Open Access This article is distributed under the terms of the Creative Commons Attribution 4.0 International License (http://creativecommons.org/licenses/by/4.0/), which permits unrestricted use, distribution, and reproduction in any medium, provided you give appropriate credit to the original author(s) and the source, provide a link to the Creative Commons license, and indicate if changes were made. The Creative Commons Public Domain Dedication waiver (http://creativecommons.org/publicdomain/zero/1.0/) applies to the data made available in this article, unless otherwise stated.

alkaline protease, which could be used for leather processing [11-14]. To further elevate the protease production, better knowledge regarding how it is regulated would be necessary. We are interested in the gene $s c o C$ (also called as hpr) because it has been shown to be a pleiotropic regulator in B. subtilis and its homolog also exits in B. pumilus [15]. scoC was first recognized in the study of $B$. subtilis mutants which could over-produce alkaline and neutral proteases [16] and showed a glucose-insensitive sporulation phenotype [17]. Later, $s c o C$ was cloned [18] and its recombinant protein could bind a consensus DNA element (5'-RATANTATY-3') that lies upstream of the aprE (encoding alkaline protease) and $n p r E$ (also called as $\operatorname{aprN}$, encoding neutral protease), which acted as a negative regulator of 
transcription of aprE and nprE [19]. In addition, ScoC was also demonstrated to regulate multiple target genes involved in a broad range of biological processes such as the signaling peptide transport systems, app and opp [20] and bacilysin production in B. subtilis [21]. Furthermore, the transcriptome analysis showed that $s c o C$ regulated expression of more than 560 genes in B. subtilis, directly or indirectly [22].

Although we found $s c o C$ expression was peaked at the exponential-growing cells and significantly declined in the later growing phases [23], its exact role in B. pumilus remains unknown. In this work, we disrupted the $s c o C$ gene with homologous recombination. The $s c o C$ mutant strain showed increased extracellular protease activity and decreased bacterial motility possible due to reduced flagellar formation. These phenotypes are consistent with the transcriptome profiling changes with upregulation or downregulation of the related genes.

\section{Results}

\section{Phenotypical characterization of scoC deletion mutant}

A $s c o C$ deletion mutant strain $(\mathrm{BA06}-\Delta s c o C)$ was successfully disrupted by homologous recombination following the strategy as showed in Fig.1 and confirming by colony PCR and DNA sequencing (Additional file 1: Figure S1). Furthermore, an overexpression strain $(\Delta s c o C / s c o C+)$ was also constructed to overexpression $\mathrm{ScoC}$ on the multiple-copies plasmids (pSU03-scoC).

Firstly, we compared the growth pattern of the wild-type (wt), $s c o C$ deletion mutant (BA06- $\Delta s c o C$ ), and $s c o C / s c o C^{+}$overexpression strains. Figure 2 a showed that the defect or overexpression of $s c o C$ did not affect the cell growth in MM broth in comparison with the wt. Secondly, since the previous studies in B. subtilis showed that $\mathrm{ScoC}$ negatively regulated protease genes of aprE and $n p r E$, and $s c o C$ disruption led to significant increase of extracellular protease activity [19, 24], the total extracellular protease activity was determined in of B. pumilus (Fig. 2b). It was showed that $s c o C$ deletion caused 2 -fold increase in extracellular proteolytic activity compared to the wt at the time point of $60 \mathrm{~h}$. On the other hand, overexpression of $s c o C$ in the $\Delta s c o C / s c o C^{+}$strain reversed to diminish the increased extracellular protease activity. Like in B. subtilis, ScoC acted as a negative regulator of extracellular proteases in B. pumilus.

Next, we examined the bacterial motility on the solid and semi-solid plates with agar concentrations of 0.7 and $0.3 \%$ [25]. Figure 3 showed that the colony size of BA06- $\Delta s c o C$ was much smaller than that of the wt and $\Delta s c o C / s c o C^{+}$strains on LB plate with $0.7 \%$ agar and MM plate with $0.3 \%$ agar, respectively, indicating that both the swarming and swimming motility were compromised after $\operatorname{scoC}$ disruption. The colony expansion in diameter of BA06- $\Delta s c o C$ was statistically different from the wt and overexpression strains with $p<0.05$ and 0.01 , respectively. These results indicated that $s c o C$ could modulate the cell motility of $B$. pumilus.

Since flagellum is the movement organ of bacteria, we counted the cell number with flagella or without flagella for the three B. pumilus strains. It was found that $s c o C$ disruption reduced the flagella formation (Fig. 4). The percentage of cells with flagella were only $23.7 \%$ for BA06- $\triangle S c o C$. By contrast, the percentages were 69.8 and $71.1 \%$ for the wt and overexpression strains, respectively. Of interest, previous studies done in B. subtilis showed that many flagellar genes were downregulated in $s c o C$ deletion mutant [22]. These results suggested that decrease of cell motility of BA06- $\Delta s c o C$ was at least partially resulted from the reduction of flagella formation.

In addition, formation of endospore and biofilm was also examined. In contrast to $B$. subtilis, no significant difference was found among the three B. pumilus stains (Additional file 2: Figure S2), implicating $\mathrm{ScoC}$ also plays strain-specific role.

\section{Transcriptome profiling of scoC mutant}

To better understand the mechanism underlying the observed phenotypes in B. pumilus, we performed comparative transcriptome profiling using RNA sequencing. Overall, a total 1674 differentially expressed genes (DEGs) with the expression level $>2.5$-fold change and $p<0.01$ were identified across the three time points at which the BA06- $\triangle s c o C$ and wt cells were compared (Fig. 5a, Additional file 3: Table S1). The most DEGs were identified at the time point of $12 \mathrm{~h}$ with 531 up-regulated and 467 down-regulated. And DEGs subsequently declined at the later growth phases, suggesting that $s c o C$ may play a major role at the transition phase.

By KEGG pathway analysis, the DEGs were categorized into various metabolic pathways, of which the top 10 were displayed in Fig. 5b. Overall, the expression patterns are very similar between $B$. subtilis and $B$. pumilus after $s c o C$ disruption. The largest group with altered transcriptional level in the $s c o C$ deletion mutant belongs to the KEGG category of membrane transport [22]. For example, some putative operons involved in the metal ion transport systems (cds3101-3105; cds3029-3032) were downregulated in BA06- $\triangle s c o C$ strain (Additional file 3: Table S1). In B. subtilis, some operons like opp and $a p p$ encoding oligopeptide transport systems have been experimentally confirmed to be directly regulated by $\operatorname{scoC}$ [20]. In addition, many affected genes were also enriched in amino acid metabolism, carbohydrate metabolism, translation, transcription, etc.

Nevertheless, there are also significant differences from B. subtilis. For instance, two protease genes aprE (cds0935) and $a p r X$ (cds1594) showed same expression pattern, i.e. upregulation in both strains at 24 and $36 \mathrm{~h}$ 


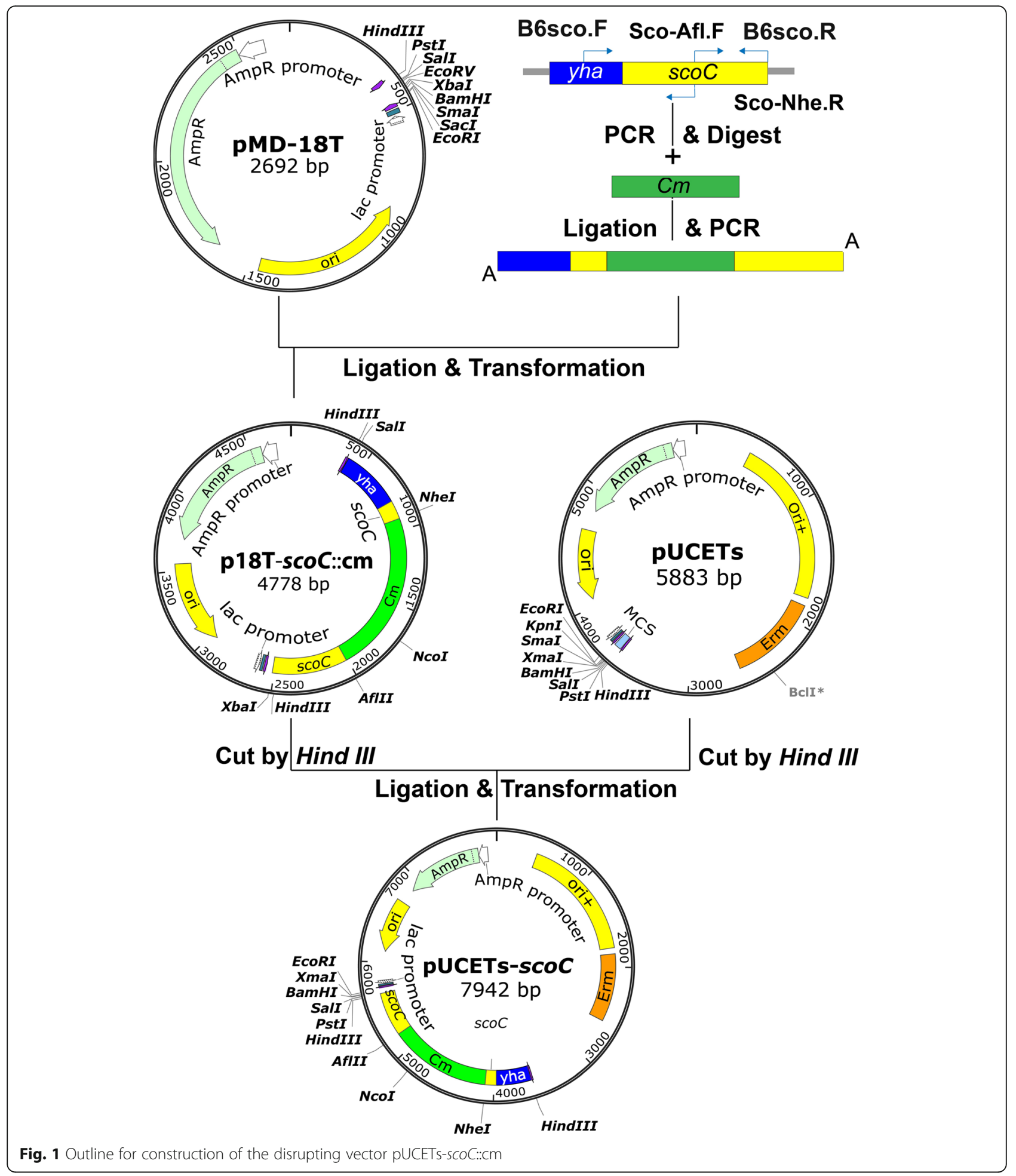

(Table 1), while the neutral protease gene aprN (cds2061) was decreased in B. pumilus but increased in B. subtilis, respectively. Furthermore, the other protease gene like epr (cds0246) and $v p r$ (cds3474) did not changed obviously in transcription level in B. pumilus after scoC deletion (Table 1). Because the proteases like AprE is regulated by both positive and negative regulators in B. subtilis, herein we examined transcriptional level of the homologous regulatory genes in $B$. pumilus. It was showed that the negative regulator gene $a b r B$ (cds0014) and $\sin R$ (cds2171) did not change (Additional file 3: Table S1). However, the sensor histidine kinase gene 


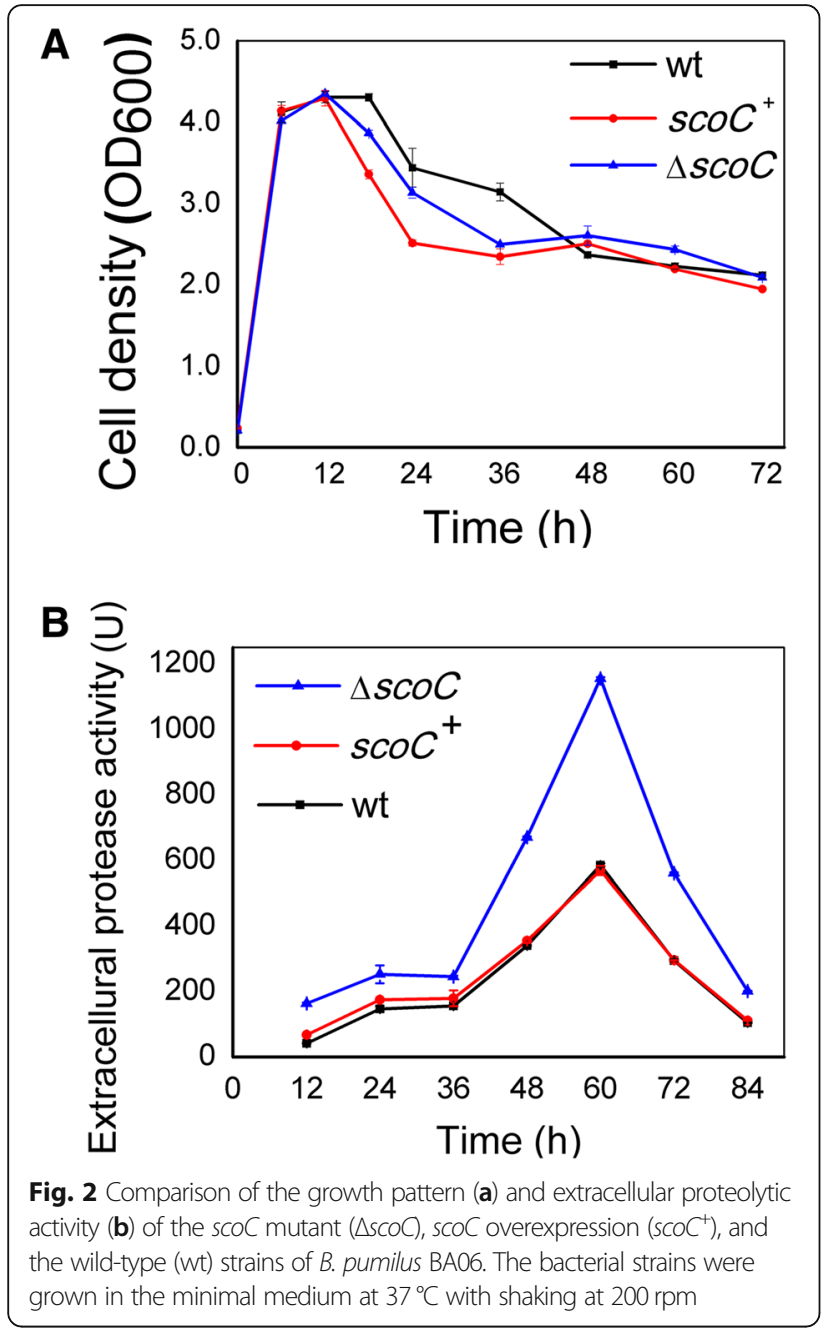

$\operatorname{degS}$ (cds3226) were upregulated at $12 \mathrm{~h}$, which may promote the phosphorylation level of DegU and in turn enhance the transcription of aprE [26]. This is consistent with increased aprE expression.

Since the scoC mutation displayed defective flagella formation (Fig. 4), we examined the transcriptional profiling of flagella-related genes. In B. pumilus, these genes are organized as several operons (like $f l c / c h e$ and $\operatorname{mot} A B$ ) or individually scattered in the genome (Additional file 4: Figure S3). Overall, 63 genes categorized into the KEGG Bacterial Motility (k02035) and Flagellar Assembly (k02040) pathways have a trend to downregulation in BA06- $\Delta s c o C$ strain (Fig. 6a, Additional file 3: Table S1). Nevertheless, seldom genes were upregulated. For example, the flgM gene (cds3219, encoding an anti-sigma factor) were upregulated for about 3-fold at $12 \mathrm{~h}$ (Additional file 4: Figure S3). In the fla/che operon, the upregulated genes (fliEFGH, fliJ) may be transcribed from another independent promoter [27]. In addition, the gene swrA encoding a master regulator of motility that activates the cell motility in B. subtilis

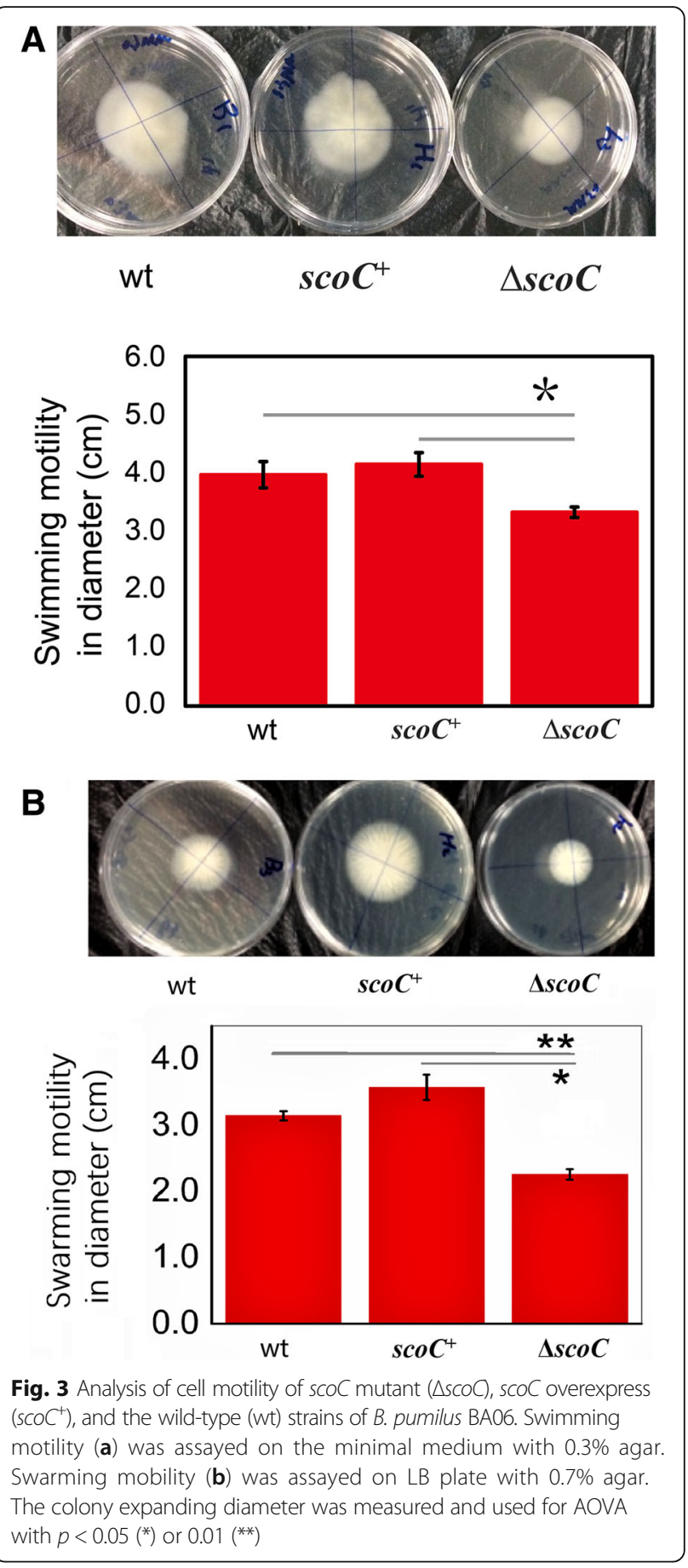

[28], was also upregulated in $s c o C$ deletion mutant of $B$. pumilus. Taken together, the transcriptome data suggest that the compromised flagella formation is at least in part due to downregulation of the flagellar structural genes after $s c o C$ deletion.

Another group of DEGs is enriched into the KEGG Cell Growth pathway (99978). Most of these genes related to sporulation were continually upregulated at all three time points in BA06- $\Delta \mathrm{scoC}$ (Fig. 6b), consistent 


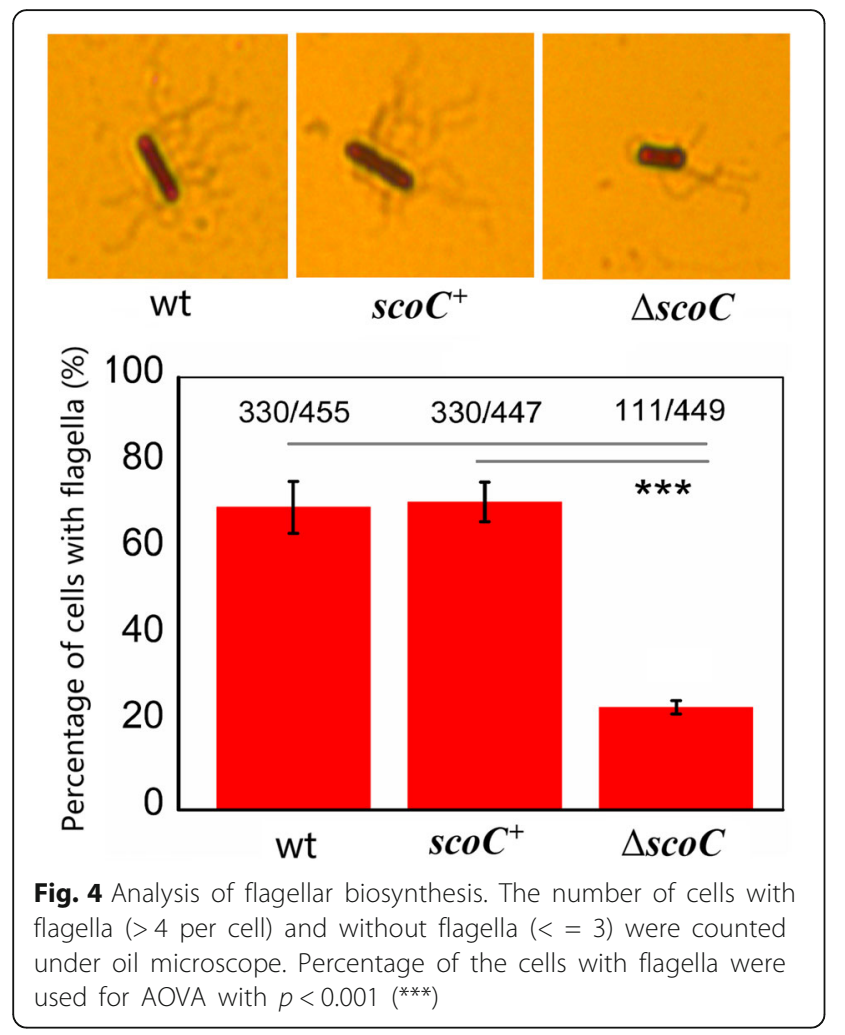

with the finding that $s c o C$ disruption promoted sporulation in B. subtilis $[17,24]$. However, no overt enhanced sporulation was observed in B. pumilus (Additional file 2: Figure S2A), implicating there might existed additional regulatory pathway in $B$. pumilus. Of note, these sporulation-related genes are still not found to interact directly with ScoC. Therefore, scoC may undergo an indirect pathway to regulate sporulation. For example, scoC can suppress sporulation by acting as a repressor of the signaling peptide transport systems, opp and $a p p$ in $B$. subtilis [20]. Indeed, we found the opp operon (opp ABCDF, cds1038-1042) was downregulated at $12 \mathrm{~h}$ and then upregulated at $24 \mathrm{~h}$ in B. pumilus scoC mutant (Additional file 3: Table S1).

Lastly, to confirm the accuracy and reproducibility of the transcriptome data, 13 genes were selected for qPCR validation. RNA samples from the same cultures of MM at different growth phases were used as template. The data shown in Table S2 (Additional file 5) indicated that RNA-seq data were almost consistent with the qPCR results.

\section{Discussion}

Previous studies have demonstrated that $s c o C$ negatively regulated a plethora of genes or operons in B. subtilis through direct binding to a consensus DNA element located in promoter region of these genes [16-20]. ScoC homologs have been found in many Bacillus species other than B. subtilis, but their functions remained largely unknown. In this work, we showed that disruption of scoC gene in B. pumilus increased extracellular protease activity and decreased cell motility, which could be attributed to transcriptional alternation of ScoC target genes.

Our data indicated scoC disruption leads to many genes to alter the transcriptional level across different growth phases. The large number of DEGs up to 1098 were enriched at $12 \mathrm{~h}$, the transition point between exponential growth and stationary phase [23]. Since ScoC is recognized as one of the transition-state regulators that silence expression of genes involved in secondary metabolisms at the exponential growth phase [29]. By KEGG analysis, many genes categorized into the secondary metabolisms were identified to be upregulated, such as sporulation related genes and various enzymes after scoC disruption. On contrast, some genes involved in
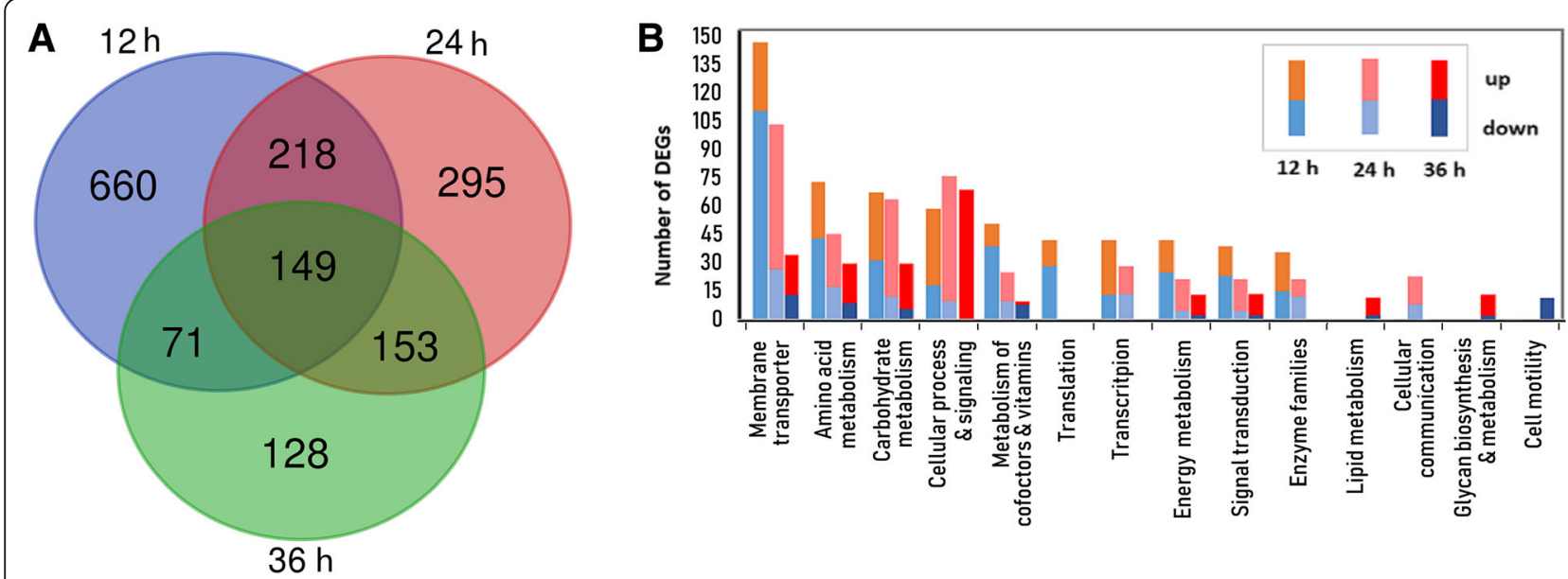

Fig. 5 Venn diagram analysis (a) and KEGG enrichment (b) of the differentially expressed genes (DEGs) between scoC mutant and the wild-type strain of B. pumilus BA06 across three time-points 
Table 1 Relative expression level (TPM) of the protease genes of the scoC mutant ( $\triangle s c 0 C$ ) and the wild-type (wt) strain of B. pumilus BA06 across three time-points

\begin{tabular}{|c|c|c|c|c|c|c|c|c|}
\hline \multirow[t]{2}{*}{ Gene ID } & \multirow[t]{2}{*}{ Gene } & \multirow[t]{2}{*}{ Protein } & \multicolumn{3}{|c|}{ B. pumilus (wt) } & \multicolumn{3}{|c|}{$\triangle$ scoC mutant } \\
\hline & & & $12 \mathrm{~h}$ & $24 \mathrm{~h}$ & $36 \mathrm{~h}$ & $12 \mathrm{~h}$ & $24 \mathrm{~h}$ & $36 \mathrm{~h}$ \\
\hline CDS0232 & wprA & Cell wall-associated protease & 121 & 72 & 127 & 120 & 140 & 144 \\
\hline CDS0246 & epr & Minor extracellular protease & 58 & 50 & 47 & 45 & 40 & 33 \\
\hline CDS0935 & aprE & Subtilisin E & 10,201 & 5730 & 11,622 & $27,522^{a}$ & $53,512^{\mathrm{a}}$ & $33,455^{a}$ \\
\hline CDS1190 & isp & Major intracellular protease & 10,281 & 2299 & 6415 & $3490^{\mathrm{a}}$ & $5368^{\mathrm{a}}$ & 8946 \\
\hline CDS1401 & $b p r$ & Bacillopeptidase F & 439 & 233 & 597 & 282 & $499^{a}$ & 353 \\
\hline CDS1594 & aprX & Serine protease AprX & 386 & 16 & 55 & $24^{\mathrm{a}}$ & $388^{\mathrm{a}}$ & $1002^{\mathrm{a}}$ \\
\hline CDS2061 & aprN & Subtilisin NAT & 274 & 188 & 292 & $61^{\mathrm{a}}$ & $42^{a}$ & $51^{\mathrm{a}}$ \\
\hline CDS3474 & $v p r$ & Minor extracellular protease & 390 & 465 & 484 & 297 & 218 & 199 \\
\hline
\end{tabular}

indicating the significant fold-change with $|\log (\mathrm{FC})|>1.3219$ and $\mathrm{p}<0.01$

primary metabolisms like membrane transport and amino acid metabolism were also down-regulated (Fig. 5b). Therefore, we conclude that $s c o C$ may play a leading role in transcriptional regulation at the metabolic transition time.

B. pumilus encodes several extracellular proteases, of which AprE is the major one accounting for more than $70 \%$ of the total extracellular proteolytic activity [30]. In this work, we found the total extracellular proteolytic activity of the $s c o C$ mutant was significantly increased, which could be ascribed to the increase of aprE transcription. aprE has been showed as a direct target by $\mathrm{ScoC}$ [30], which is also regulated by multiple transcription factors such as AbrB, DegU/DegS, SinR, and Spo0A [31]. In viewing of our transcriptome data, DegS and Spo0A may partially contribute to increased transcription of aprE in the BA06- $\Delta s c o C$ strain. Unexpected, apr $N$ encoding neutral protease was seriously downregulated in $s c o C$ deletion mutant (Table 1). That is totally different from B. subtilis, in which aprN was a direct target of $\mathrm{ScoC}[16,19]$. Therefore, scoC may underly additional mechanism to regulate expression of $\operatorname{aprN}$. In addition, the transcription level of epr and $v p r$ did not change significantly (Table 1). However, epr was reported to be only co-repressed by $\mathrm{ScoC}$ and $\mathrm{SinR}$ and individual mutant of $s c o C$ or $\sin R$ did not repress epr's expression in B. subtilis [32]. The expression of vpr was not mediated by ScoC in B. subtilis [33]. Conclusively, these protease-encoding genes may be differentially regulated by $\mathrm{ScoC}$ in B. pumilus.

Another phenotypical change caused in $s c o C$ mutant is decrease of cell motility (Fig. 3) and defective flagella formation (Fig. 4). As expected, many of these genes involved in flagellar biosynthesis were indeed down-regulated (Fig. 6a). The similar observation was also found in in B. subtilis [22]. In B. cereus, the flagella-associated genes were upregulated in the swarming cells in comparison with the non-swarming cells [34]. All the experimental evidences indicate that the flagellar biosynthesis as well as cell mobility is associated with expression level of the relative genes. In B. subtilis, the studies on regulatory mechanism of flagellar biosynthesis are focusing on the fla/che operon, which containing 32 genes that encode the flagellar basal-body rod proteins. A SwrA protein has been reported as a master regulator in regulation of flagellar biosynthesis [28]. The gain-of function mutations in $s w r A$ increased the proportion of motile cells and the flagellar number per cells $[25,35]$. Although our data showed that swrA (cds3194) was upregulated by about 3 -fold at $12 \mathrm{~h}$ (Additional file 3: Table S1), the flagella formation was comprised (Fig. 4). A reasonable explain of this discrepancy is existence of additional regulators. For example, unphosphorylated DegU could bind an inverted repeat-like upstream of the fla/che promoter and then activated transcription; while the phosphorylated DegU played a contrast role to depress its expression by binding to another inverted repeat-like sequence in fla/che operon [36, 37]. In addition, SwrA activation of the fla/che expression may require DegU [38, 39], which may be compensated by enhancement of phosphorylation DegU by DegS because $\operatorname{degS}$ was up-regulated in transcription in B. pumilus scoC mutant.

In addition, ScoC may regulate flagellar biosynthesis through SigD-mediated pathway. Almost all the flagella-related genes belong to SigD regulon [40]. The gene $f \lg M$ to encode anti-sigma factor against sigD was positively regulated by $\mathrm{ScoC}$ via binding to its promoter in B. subtilis [41, 42]. Our data showed that flgM (cds3219) was really upregulated by more than 4-fold at $12 \mathrm{~h}$ (Additional file 3: Table S1). Taken together, ScoC may modulate the flagellar biosynthesis through direct or indirect pathways in B. pumilus.

For Bacillus, it is an important to produce endospores under stress conditions. The formation of endospores begins with a period of stable growth of nutrient-poor 


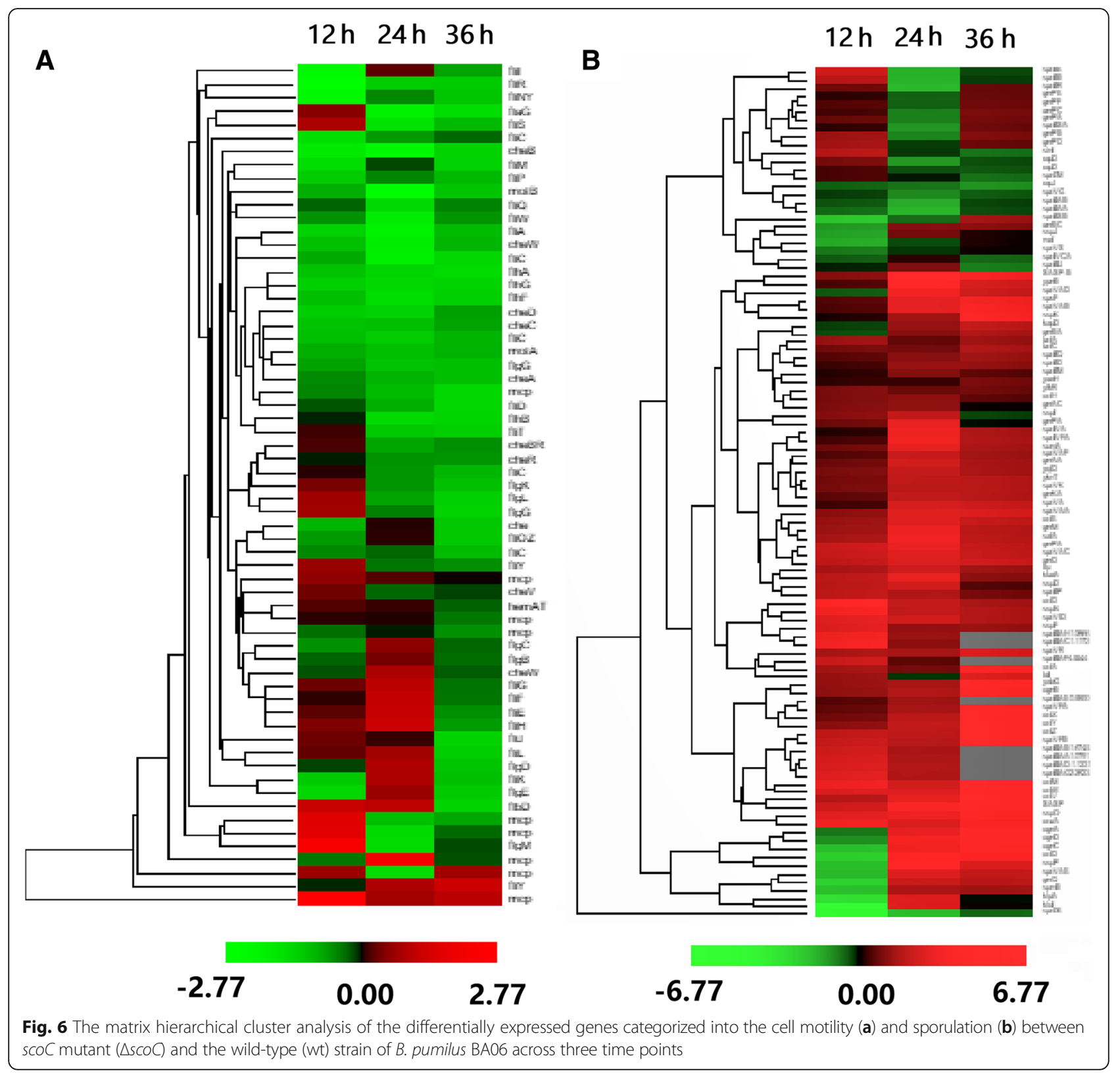

and is restricted by advanced hierarchical regulation [43]. Spo0A is the master regulator to initiate endospore formation [44]. According to earlier studies, ScoC is a negative regulator for sporulation of $B$. subtilis $[17,18]$. Our transcriptome data demonstrated that many sporulation genes were upregulated after $s c o C$ deletion (Fig. 6b). We did not observe any significant change of sporulation between the wt and $s c o C$ mutation strains. Since no target gene involved in sporulation has been identified [40], regulatory role of ScoC on sporulation remains unknown in B. pumilus.

\section{Conclusions}

In conclusion, we found that disruption of $s c o C$ gene in $B$. pumilus caused increased extracellular protease activity, decreased motility and compromised flagella formation. All these features are well correlated with the transcriptional changes of the corresponding genes. However, our transcriptome data provides new hints to further investigate the putative target genes of ScoC in B. pumilus.

\section{Materials and methods}

Bacterial strains, plasmids and culture conditions

The bacterial strains used here are present in Table 2 . The primers used to construct each plasmid are listed Table S3 (Additional file 6). All strains were grown in Luria-Bertani (LB) broth at $37^{\circ} \mathrm{C}$ unless stated otherwise. When appropriate, LB broth was supplemented 
Table 2 The bacterial strains and plasmids used in this work

\begin{tabular}{|c|c|c|}
\hline Strains and plasmids & Description & Reference \\
\hline \multicolumn{3}{|l|}{ Strains } \\
\hline $\begin{array}{l}\text { Escherichia coli } \\
\text { DH5a }\end{array}$ & $\begin{array}{l}\text { supE } 44 \Delta / a c \cup 169 \text { ( } 80 \text { lacZLM15) } \\
\text { hdsR17 recA1 endA1 gyrA96 thi-1 } \\
\text { relA1 }\end{array}$ & Lab stock \\
\hline $\begin{array}{l}\text { Bacillus pumilus } \\
\text { BA06 }\end{array}$ & The wild-type strain & Lab stock \\
\hline $\begin{array}{l}\text { B. pumilus } \\
\text { BA06- } \triangle s c 0 C\end{array}$ & $\triangle \mathrm{scoC} ; \mathrm{Cm}$ & This work \\
\hline $\begin{array}{l}\text { B. pumilus } \\
\left(\Delta s \mathrm{sco} / \mathrm{scoC}^{+}\right)\end{array}$ & $\operatorname{scoC}^{+} ;$Kan & This work \\
\hline \multicolumn{3}{|l|}{ Plasmids } \\
\hline pMD-18T & T-vector; Amp; high copies & TaKaRa Co. \\
\hline pHCMCO2 & $\mathrm{Cm}$; high copies & {$[45]$} \\
\hline pUCETs & $\begin{array}{l}\text { Shuttling vector (E. coli and Bacillus); } \\
\text { temperature-sensitive ori; Erm; low } \\
\text { copies }\end{array}$ & {$[46]$} \\
\hline pSU03-Ap & $\begin{array}{l}\text { expression vector (Bacillus); high } \\
\text { copies }\end{array}$ & {$[47]$} \\
\hline p18T-scoC:: cm & scoC::Cm; Amp; high copies & This work \\
\hline pUCETs:scoC::: cm & scoC:: Cm; Erm; low copies & This work \\
\hline pSU03-scoC & $\begin{array}{l}\text { scoC; promoter of GAPD; Kan; } \\
\text { high copies }\end{array}$ & This work \\
\hline
\end{tabular}

with $50 \mu \mathrm{g} / \mathrm{mL}$ kanamycin $(\mathrm{Km})$ or $100 \mu \mathrm{g} / \mathrm{mL}$ ampicillin (Amp) for Escherichia coli, $5 \mu \mathrm{g} / \mathrm{mL}$ erythromycin (Erm) or $10 \mu \mathrm{g} / \mathrm{mL}$ chloramphenicol (Cm) for B. pumilus.

All the restriction enzymes were purchased from Thermo Fisher Scientific Inc. (Waltham, MA, USA). T4 DNA ligase, $P f u$ DNA polymerase, Taq DNA polymerase, RTase and the Genome DNA Eraser Kit were obtained from TaKaRa Bio. Co. (Dalian, China). $2 \times$ Real Time PCR EasyTM -SYBR Green I kit was purchased from Chengdu Fuji Biotechnology Co., Ltd. (Chengdu, China). TRIzol reagent was purchased from Invitrogen Co. (Carlsbad, CA, USA). Gel Recovery Kit and PCR Cycle recovery Kit was obtained from Omega Bio-tek, Inc. (Norcross, GA, USA).

\section{Construction of vectors}

To construct the disruption vector, two DNA fragments covering the full scoC gene as well as its flanked sequences was amplified by Pfu DNA polymerase with primers (B6sco.F/Sco-Afl.F, and Sco-Nhe/B6sco.R) using genomic DNA of B. pumilus BA06 as template. The PCR fragments were purified and digested with $A f l$ II and Nhe I, respectively. A 1095-bp Afl II-Nhe I fragment containing the chloramphenicol resistance gene $(\mathrm{Cm})$ was obtained to digest the plasmid pHCMC02 [45]. Then, the $\mathrm{Cm}$ fragment was mixed and ligated with the above two PCR fragments using T4 DNA ligase. The ligated product was amplified using primers (B6sco.F and B6sco.R) and Taq DNA polymerase. The expected PCR product was directly cloned into pMD-18 T (Takara, Dalian, China) by A/T cloning using T4 DNA ligase, resulting plasmid p18T-scoC::cm. After confirmed by DNA sequencing, the $s c o C:: \mathrm{cm}$ fragment was obtained by digested with Hind III and inserted into Hind III-digested pUCETs [46] using T4 DNA ligase. The resulted vector pUCETs-scoC::Cm was used to disrupt the scoC gene.

The vector pSU03-scoC was constructed to overexpress $s c o C$ in B. pumilus. The promoter of the gene encoding glyceraldehyde-3-phosphate dehydrogenase (GAPDH) and the coding sequence of $s c o C$ were amplified using the primers (B06Pgpd.F/B06Pgpd.R, B06P-scoC.F/B06-scoC.R), respectively. And the two PCR fragments were recombined by overlapped PCR with the primers (B06Pgpd.F/ B06-scoC.R). The resulting DNA fragment was digested with Nde I and Xho I. The vector sequence of pSU03-AP [47] was amplified by PCR using Pfu DNA polymerase and primers (pSU03 $\triangle$ Ap.F/pSU03 AAp.R) and digested with Nde I and Xho I. Then, the above two fragments were ligated with T4 DNA ligase. The resulting plasmid was assigned as pSU03-scoC. A His6-tag was added at the 5 -upstream of $s c o C$. The inserted sequence was confirmed by DNA sequencing.

During the vector construction, transformation of E. coli cells was performed as described by Sambrook et al. [48].

\section{Electroporation in B. pumilus BA06}

The transformation of B. pumilus BA06 was referred to the high-osmolarity electroporation protocol in B. subtilis [49] with some modification. Briefly, the competent cells of B. pumilus BA06 were prepared as following: 0.5 $\mathrm{mL}$ of overnight culture in LB broth was transferred into $50 \mathrm{~mL}$ of $\mathrm{LB}$ broth (containing $0.5 \mathrm{M}$ sorbitol and $5 \%$ betaine) and incubated at $37^{\circ} \mathrm{C}$ up to OD600 to about 1.0; the cells were harvested by centrifugation at 5000 $\mathrm{rpm}$ and $4{ }^{\circ} \mathrm{C}$ for $10 \mathrm{~min}$; after three washes with $50 \mathrm{~mL}$ of ice-cold washing buffer $(0.5 \mathrm{M}$ sorbitol, $0.5 \mathrm{M}$ mannitol, $10 \%$ glycerol and $7.5 \%$ betaine), the cells were re-suspended in $1 \mathrm{~mL}$ electroporation buffer $(0.5 \mathrm{M}$ sorbitol, $1 \mathrm{M}$ mannitol, 10\% Glycerol and 7.5\% betaine).

In the electroporation trials, $80 \mu \mathrm{L}$ competent cells were mixed with 1-5 $\mu \mathrm{L}$ DNA $(0.1-0.5 \mu \mathrm{g})$. And then, the mixture was transferred into an electroporation cuvette (0.1$\mathrm{cm}$ electrode gap). The cells were exposed to a single electrical pulse (2400 V, $25 \mu \mathrm{F}, 200 \Omega$ ) using Bio-Rad MicroPulser (Bio-Rad, USA). Immediately following the electrical discharge, $1 \mathrm{~mL}$ recovery medium (LB containing $0.5 \mathrm{M}$ sorbitol and $0.38 \mathrm{M}$ mannitol) were added to the cells. After incubating at $37^{\circ} \mathrm{C}$ with vigor shaking for $3 \mathrm{~h}$ or longer, the cells were plated on LB-agar plates with appropriate antibiotic. Following the above protocol, dozens or up to hundreds of colonies per microgram plasmid DNA could be formed dependent upon various plasmids. 


\section{Screening of $s c o C$ deletion mutant}

The $B$. pumilus transformant hosting the vector pUCETs-scoC::Cm was inoculated in $2 \sim 3 \mathrm{~mL}$ LB broth with $5 \mu \mathrm{g} / \mathrm{mL}$ Erm and $10 \mu \mathrm{g} / \mathrm{mL} \mathrm{Cm}$ and incubated at $30^{\circ} \mathrm{C}$ for $12-18 \mathrm{~h}$. A $0.5-\mathrm{mL}$ culture was transferred into $50 \mathrm{~mL} \mathrm{LB}$ containing $10 \mu \mathrm{g} / \mathrm{mL} \mathrm{Cm}$ in a $250-\mathrm{mL}$ flask and incubated for $36 \mathrm{~h}$ at the same temperature. After then, the temperature was elevated to $42^{\circ} \mathrm{C}$ and the culture was incubated for another $24 \mathrm{~h}$ with shaking to diminish the plasmid DNA. Finally, the cells were diluted to $10^{5}-10^{6}$ cells $/ \mathrm{mL}$ with sterile water and dispensed onto the LB plate with $10 \mu \mathrm{g} / \mathrm{mL} \mathrm{Cm}$. The plates were incubated at $42{ }^{\circ} \mathrm{C}$ until the colonies were formed. The same colony was picked up and dotted on two LB plates with $10 \mu \mathrm{g} / \mathrm{mL} \mathrm{Cm}$ and with $5 \mu \mathrm{g} / \mathrm{mL}$ Erm and $10 \mu \mathrm{g} /$ $\mathrm{mL} \mathrm{Cm}$, respectively. After incubating at $30^{\circ} \mathrm{C}$ for about $24 \mathrm{~h}$, the colonies growing only on LB plate with $\mathrm{Cm}$ and not on the plate amended with $\mathrm{Cm}$ and Erm were picked up for further identification by colony-PCR. The primers (Id-ScoC.F/Id-cm3.R, and Id-cm5.F/Id-scoC.R/) were used to amply the DNA sequences to cover the integrating sites in the genome, which were confirmed by DNA sequencing.

\section{Growth curve and extracellular protease activity assay}

Three B. pumilus BA06 strains including scoC deletion mutant (BA06- $\Delta \mathrm{scoC}), \Delta s c o C / s c o C^{+}$overexpression, and the wt strains were inoculated into $50 \mathrm{~mL}$ minimal medium (MM, $1.0 \mathrm{~g} / \mathrm{L}$ sodium citrate, $2.0 \mathrm{~g} / \mathrm{L}\left(\mathrm{NH}_{4}\right)_{2} \mathrm{SO}_{4}, 14.0 \mathrm{~g} / \mathrm{L}$ $\mathrm{K}_{2} \mathrm{HPO}_{4}, 6.0 \mathrm{~g} / \mathrm{L} \mathrm{KH}_{2} \mathrm{PO}_{4}, 0.2 \mathrm{~g} / \mathrm{L} \mathrm{MgSO}_{4}, 2.5 \mathrm{~g} / \mathrm{L}$ Yeast extract and $5.0 \mathrm{~g} / \mathrm{L}$ D-glucose) and incubated at $37^{\circ} \mathrm{C}$ with shaking at $200 \mathrm{rpm}$. At the indicated time points, $2 \times 1 \mathrm{~mL}$ culture was sampled from each flask. The cell density was measured at $\mathrm{OD}_{600}$. The extracellular protease activity was determined using casein as substrate by the Folin-Phenol method as described [50]. All the experiments were repeated in triplicate.

\section{Motility analysis}

The motility analysis was performed as described previously [25]. Briefly, one microliter of the freshly overnight culture of each strain grown in LB broth $\left(\mathrm{OD}_{600}\right.$ 1.0) was seeded at the center of the motility assay plates (90-mm in diameter) with a pipette tip. All plates were immediately air-dried at ambient temperatures $(\sim$ $37^{\circ} \mathrm{C}$ ) in a laboratory ventilator. Swimming motility was evaluated on the freshly prepared semi-liquid MM plates containing $0.3 \%$ agar. Swarming motility was evaluated on LB plates containing $0.7 \%$ agar. Photographs were taken after $24-\mathrm{h}$ incubation at $37^{\circ} \mathrm{C}$. And the diameter of motility halos was measured at the same time. All motility assay experiments were independently repeated more than three times.

\section{Flagellum staining}

Flagellum staining was performed as described by a standard method [51]. Briefly, a loop of bacterial cells was taken from the colony edge growing on MM plate (0.3\% agar) at $37^{\circ} \mathrm{C}$ for $12 \mathrm{~h}$ and dispensed in sterile water on the glass slide. After air-dried, the cells were stained with the solution A (5.0\% tannic acid, $1.5 \mathrm{~g} \%$ $\mathrm{FeCl}_{3}, 0.01 \% \mathrm{NaOH}, 2.0 \%$ formalin) for $5 \mathrm{~min}$, subsequently with the solution $\mathrm{B}\left(2.0 \% \mathrm{AgNO}_{3}\right)$ for $0.5 \mathrm{~min}$. After air-dried, the flagella were observed under oil microscope with magnification of $\times 100$ folds. The number of flagella for the cells were counted. The flagellum staining was performed by several times using the various cultures.

\section{RNA isolation, library construction and transcriptome analysis}

The cell samples of B. pumilus cultures growing in MM broth were pelleted by centrifugation at $8000 \mathrm{rpm}$ at the indicated time points $(12,24$, and $36 \mathrm{~h})$, and then re-suspended in TE buffer (1 mM EDTA and $10 \mathrm{mM}$ Tris- $\mathrm{HCl}, \mathrm{pH} 8.0$ ) supplemented with $1.5 \mathrm{mg} / \mathrm{mL}$ lysozyme. After incubated at $37^{\circ} \mathrm{C}$ for $10 \mathrm{~min}$, the TRIzol reagent was added. The cell suspension was mixed extensively while using the gauge to disrupt the cells completely. Finally, total RNA was isolated following the instructions provided with the TRIzol reagent. The genomic DNA was removed using the Genome DNA Eraser Kit. The resulting RNAs were fragmented and reverse transcribed using random hexamers as the primer. Second strand cDNA synthesis was performed using DNA Polymerase I and RNase $\mathrm{H}$. The cDNA fragments were processed for end repair and ligated to paired end adaptors. Finally, the library was sequenced on an Illumina HiSeqTM2000.

The clean data of the wt and BA06- $\triangle$ scoC strains growing for $12 \mathrm{~h}, 24 \mathrm{~h}$ and $36 \mathrm{~h}$ were mapped to the genomic annotation by HISAT2 software [52, 53], indicating that more than $99 \%$ reads could map onto the genome (Additional file 7: Table S4). The expression level of each gene was calculated by StringTie software $[53,54]$. The number of reads in features were counted by HTseq [55] or featureCounts [56], which were imported into the edgeR software [57] to calculate differentially expressed genes (DEGs) between various samples and different time points. When the value of $\mid \log _{2}$ fold change $\mid \geq 1.3250$ and $p<0.01$, the corresponding gene was defined as the DEG.

Based on the numbers of DEGs that calculated across the three time points of $12 \mathrm{~h}, 24 \mathrm{~h}$, and $36 \mathrm{~h}$, the Venn diagram was constructed online (http://bioinformatics. psb.ugent.be/webtools/venn/) [58]. KEGG analysis was performed online (www.kegg.jp/kegg/pathway.html) [59]. The matrix hierarchical cluster analysis for the selected 
KEGG pathways was performed using PermutMatrix v.1.9.3 (www.lirmm.fr/ caraus/PermutMatrix/) [60].

\section{Quantitative real-time PCR analysis}

To confirm the transcriptome data, the quantitative real-time PCR (qPCR) was performed for the selected genes. Totally, 16 pairs of primers were designed (Additional file 8: Table S5) and the 16 sRNA gene was used as the control. The RNAs were isolated from the same cell samples as the transcriptome analysis. The reverse transcription (RT) was performed in $20 \mu \mathrm{L}$ mixture including $1 \mu \mathrm{g}$ RNA sample and $5 \mathrm{U}$ RTase (Takara, Dalian, China). The resulting cDNA was diluted by $\times 10$ folds and used as a template for qPCR. qPCR was carried out following the instruction of $2 \times$ Real Time PCR EasyTM-SYBR Green I Kit. The calculated cycle threshold (CT) was normalized to the CT of 16 sRNA amplified from the corresponding sample. Changes in mRNA levels were calculated using the $2^{-\Delta \Delta \mathrm{CT}}$ method [61].

\section{Statistical analysis}

Statistical analysis was performed with SPSS Statistics software. A $P$ value of 0.05 or 0.01 was considered significant or extreme significant.

\section{Additional files}

Additional file 1: Figure S1. Strategy of $s c 0 C$ disruption (A) and identification of the scoC deletion mutant by colony-PCR and DNA sequencing. B, left integrating site; C, right integrating site. (JPG $269 \mathrm{~kb}$ )

Additional file 2: Figure S2. Formation of endospore (A) and biofilm (B) of $s \mathrm{COC}$ mutant (BA06- $\triangle \mathrm{scoC}$ ), the wt (BA06) and overexpression $\left(\triangle \mathrm{scoC} / \mathrm{scOC}^{+}\right)$strains of B. pumilus. (PNG $355 \mathrm{~kb}$ )

Additional file 3: Table S1. The relative expression levels and the foldchange of all the genes in $\mathrm{SCOC}$ mutant (BA06- $\triangle \mathrm{scOC}$ ) and the wt (BA06) strains of B. pumilus across three time points. (XLSX $2020 \mathrm{~kb}$ )

Additional file 4: Figure S3. The organization of flagella-related genes in B. pumilus BA06 genome and their fold-change of transcription at $12 \mathrm{~h}$ between the wt and scoC mutant strains. The arrow indicates the putative transcriptional direction. (PNG $61 \mathrm{~kb}$ )

Additional file 5: Table S2. Confirmation of the transcriptional data for the selected genes by qPCR. (DOCX $17 \mathrm{~kb}$ )

Additional file 6: Table S3. The primers used to construct the vectors and for DNA sequencing. (DOCX $16 \mathrm{~kb}$ )

Additional file 7: Table S4. Overall mapped reads generated by RNA-seq onto the genome of B. pumilus BA06. (DOCX $17 \mathrm{~kb}$ )

Additional file 8: Table S5. The primers used in GPCR to confirm the transcriptome data for the selected genes. (DOCX $18 \mathrm{~kb}$ )

\section{Abbreviations}

Amp: Ampicillin; Cm: Chloramphenicol; DEG: Differentially expressed gene; Erm: Erythromycin; Kan: Kanamycin; LB: Luria-Bertani; PCR: Polymerase chain reaction; qPCR: Quantitative real-time PCR; RT: Reverse transcription; wt: Wild-type

\section{Funding}

This research was conducted with the financial support of the National Natural Science Foundation of China under Grant Number of 31171204 and 21472132. The funding bodies played no role in design of the study, collection, analysis and interpretation of data or in writing the manuscript.

\section{Availability of data and materials}

The transcriptome data used in this work were deposited. All transcriptome data used in this study were deposited in the NCBI databases under BioProject: PRJNA51 1594 (https://www.ncbi.nlm.nih.gov/bioproject/511594).

\section{Authors' contributions}

HF conceived the study and drafted the manuscript; LLH performed the experiments and participated in drafting the manuscript; YCL performed data analysis. CCM performed the partial experiments. All authors read and approved this final manuscript.

Ethics approval and consent to participate

Not applicable.

\section{Consent for publication}

Not applicable.

Competing interests

The authors declare that they have no competing interests.

\section{Publisher's Note}

Springer Nature remains neutral with regard to jurisdictional claims in published maps and institutional affiliations.

Received: 25 December 2018 Accepted: 8 April 2019

Published online: 30 April 2019

\section{References}

1. Baweja M, Tiwari R, Singh PK, Lata N, Pratyoosh S. An alkaline protease from Bacillus pumilus MP27: functional analysis of its binding model toward its applications as detergent additive. Front Microbiol. 2016;7:1195.

2. Liang C, Gui X, Zhou C, Xue Y, Ma Y, Tang SY. Improving the thermoactivity and thermostability of pectate lyase from Bacillus pumilus, for ramie degumming. Appl Microbiol Biotechnol. 2015;99:2673-82.

3. Kaur P, Bhardwaj NK, Sharma J. Process optimization for hyper production of xylanase via statistical methodology from isolated Bacillus pumilus $3 \mathrm{GAH}$ using lignocellulosic waste. Biocatal Agricult Biotechnol. 2016;6:159-67.

4. Asha PC, Prema P. Production of cellulase-free endoxylanase from novel alkalophilic thermotolerent Bacillus pumilus by solid-state fermentation and its application in wastepaper recycling. Bioresour Technol. 2007;98:485-90.

5. Balasubramanian N, Simöes N. Bacillus pumilus, S124A carboxymethyl cellulase; a thermo stable enzyme with a wide substrate spectrum utility. Int J Biol Macromol. 2014;67:132-9.

6. Yong SL, Kim KY. Antagonistic potential of Bacillus pumilus L1 against rootknot nematode, Meloidogyne arenaria. J Phytopathol. 2016;164:29-39.

7. Brack C, Mikolasch A, Schlueter R, Otto A, Becher D, Wegner U, Albrecht D, Riedel K, Schauer F. Antibacterial metabolites and bacteriolytic enzymes produced by Bacillus pumilus during bacteriolysis of Arthrobacter citreus. Mar Biotechnol. 2015:17:290-304.

8. Food Safety Authority E. Scientific opinion of the scientific committee on the introduction of a qualified presumption of safety (QPS) approach for assessment of selected microorganisms referred to EFSA. vol. 578. 2007.

9. Wemhoff S, Meinhardt F. Generation of biologically contained, readily transformable, and genetically manageable mutants of the biotechnologically important Bacillus pumilus. Appl Microbiol Biotechnol. 2013;97:7805-19.

10. Küppers T, Steffen V, Hellmuth $H_{1} \mathrm{O}^{\prime}$ Connell $\mathrm{T}$, Bongaerts J, Maurer $\mathrm{KH}$, Wiechert W. Developing a new production host from a blueprint: Bacillus pumilus as an industrial enzyme producer. Microbiol Cell Fact. 2014;13:46.

11. Zhao H-Y, Feng $\mathrm{H}$. Engineering Bacillus pumilus alkaline serine protease to increase its low-temperature proteolytic activity by directed evolution. BMC Biotechnol. 2018;18:34

12. Huang $\mathrm{R}$, Yang $\mathrm{Q}$, Feng $\mathrm{H}$. Single amino acid mutation alters thermostability of the alkaline protease from Bacillus pumilus: thermodynamics and temperature dependence. Acta Biochim Biophys Sin. 2015;47:98-105. 
13. Wang HY, Liu DM, Liu Y, Cheng CF, Ma QY, Huang Q, Zhang YZ. Screening and mutagenesis of a novel Bacillus pumilus strain producing alkaline protease for dehairing. Lett Appl Microbiol. 2007:44:1-6.

14. Huang $Q$, Peng $Y$, Li X, Wang $H$, Zhang Y. Purification and characterization of an extracellular alkaline serine protease with dehairing function from Bacillus pumilus. Curr Microbiol. 2003;46:169-73.

15. Zhao CW, Wang HY, Zhang YZ, Feng H. Draft genome sequence of Bacillus pumilus BA06, a producer of alkaline serine protease with leather-dehairing function. J Bacteriol. 2012;194:6668-9.

16. Higerd TB, Hoch JA, Spizizen J. Hyperprotease-producing mutants of Bacillus subtilis. J Bacteriol. 1972;112:1026-8.

17. Dod B, Balassa G, Raulet E, Jeannoda V. Spore control (SCO) mutants in Bacillus subtilis. II. Sporulation and the production of extracellular proteases and amylases by sco mutants. Mol Gen Genet. 1978;163:45-56.

18. Perego M, Hoch JA. Sequence analysis and regulation of the hpr locus, a regulatory gene for protease production and sporulation in Bacillus subtilis. J Bacteriol. 1988;170:2560-7.

19. Kallio PT, Fagelson JE, Hoch JA, Strauch MA. The transition state regulator Hpr of Bacillus subtilis is a DNA-binding protein. J Biol Chem. 1991;266:13411-7.

20. Koide A, Perego M, Hoch JA. ScoC regulates peptide transport and sporulation initiation in Bacillus subtilis. J Bacteriol. 1999:181:4114-7.

21. Inaoka T, Wang G, Ochi K. ScoC regulates bacilysin production at the transcription level in Bacillus subtilis. J Bacteriol. 2009;191:7367-71.

22. Caldwell R, Sapolsky R, Weyler W, Maile RR, Causey SC, Ferrari E. Correlation between Bacillus subtilis scoC phenotype and gene expression determined using microarrays for transcriptome analysis. J Bacteriol. 2001;183:7329-40.

23. Han L-L, Shao H-H, Liu Y-C, Liu G, Xie C-Y, Cheng X-J, Wang H-Y, Tan X-M, Feng $\mathrm{H}$. Transcriptome profiling analysis reveals metabolic changes across various growth phases in Bacillus pumilus BA06. BMC Microbiol. 2017;17:156.

24. Ferrari E, Henner DJ, Perego M, Hoch JA. Transcription of Bacillus subtilis subtilisin and expression of subtilisin in sporulation mutants. J Bacteriol. 1988;170:289-95.

25. Calvio C, Celandroni F, Ghelardi E, Amati G, Salvetti S, Ceciliani F, Galizzi A, Sensi S. Swarming differentiation and swimming motility in Bacillus subtilis are controlled by swrA, a newly identified dicistronic operon. J Bacteriol. 2005;187:5356-66

26. Msadek T, Kunst F, Henner D, Klier A, Rapoport G, et al. Signal transduction pathway controlling synthesis of a class of degradative enzymes in Bacillus subtilis: expression of the regulatory genes and analysis of mutations in degS and degU. J Bacteriol. 1990;172:824-34.

27. Ababneh QO, Herman JK. CodY regulates SigD levels and activity by binding to three sites in fla/che operon. J Bacteriol. 2015;197:2999-3006.

28. Patrick JE, Kearns DB. Swarming motility and the control of master regulator of flagellar biosynthesis. Mol Microbiol. 2012;8:14-23.

29. Strauch MA, Hoch JA. Transition-state regulators: sentinels of Bacillus subtilis post-exponential gene expression. Mol Microbiol. 1993;7:337-42

30. Toymentseva A, Mascher T, Sharipova MR. Regulatory characteristics of Bacillus pumilus protease promoters. Curr Microbiol. 2017;74:550-9.

31. Abe S, Yasumura A, Tanaka T. Regulation of Bacillus subtilis aprE expression by $g \ln A$ through inhibition of $s \mathrm{COC}$ and $\sigma^{\mathrm{D}}$-dependent $\operatorname{deg} R$ expression. J Bacteriol. 2009;191:3050-8.

32. Kodgire $P$, Dixit M, Rao KK. ScoC and SinR negatively regulate epr by corepressor in B. subtilis. J Bacteriol. 2006;188:6425-8.

33. Barbieri G, Voigt B, Albrecht D, Hecker M, Albertini AM, Sonenshein AL, Ferrari E, Belitsky BR. CodY regulates expression of the Bacillus subtilis extracellular proteases Vpr and Mpr. J Bacteriol. 2015;197:1423-32.

34. Salvetti S, Faegri K, Ghelardi E, Kolsto A-B, Senesi S. Global gene expression profile for swarming Bacillus cereus bacteria. Appl Environ Microbiol. 2011;77: 5149-56.

35. Kearns DB, Losick R. Swarming motility in undomesticated Bacillus subtilis. Mol Microbiol. 2003;49:581-90.

36. Calvio C, Osera C, Amati G, Galizzi A. Autoregulation of swrAA and motility in Bacillus subtilis. J Bacteriol. 2008;190:5720-8.

37. Tsukahara K, Ougura M. Promoter selectivity of the Bacillus subtilis response regulator DegU, a positive regulator of the fla/che operon and sacB. BMC Microbiol. 2008:8:8

38. Ogura M, Tsukahara K. SwrA regulates assembly of Bacillus subtilis DegU via its interaction with N-terminal domain of DegU. J Biochem. 2012;151:643-55.

39. Mordini S, Osera C, Marini S, Scavone F, Bellazzi R, Galizzi A, Calvio C. The role of SwrA, DegU and $P_{D 3}$ in fla/che expression in B. subtilis. PLoS One. 2013;8:e85065
40. Arrieta-Ortiz ML, Hafemeister C, Bate AR, et al. An experimentally supported model of the Bacillus subtilis global transcriptional regulatory network. Mol Syst Biol. 2015;11:839.

41. Kodgire P, Rao KK. Hag expression in Bacillus subtilis is both negatively and positively regulated by ScoC. Microbiol. 2009;155:142-9.

42. Kodgire P, Rao K. A dual mode of regulation of flgM by ScoC in Bacillus subtilis. Can J Microbiol. 2009;55:983-9.

43. Errington J. Regulation of endospore formation in Bacillus subtilis. Nat Rev Microbiol. 2003:1:117-26.

44. Hamon MA, Lazazzera BA. The sporulation transcription factor Spo0A is required for biofilm development in Bacillus subtilis. Mol Microbiol. 2010;42: 1199-209.

45. Nguyen HD, Nguyen QA, Ferreira RC, Ferreira LCS, Tran LT, Schumann W. Construction of plasmid-based expression vectors for Bacillus subtilis full structural stability. Plasmid. 2005:54:241-8.

46. Wang C, He T-T, Song T, Zhang C-B, Wang H-Y. The construction and application of a genetic manipulation system for Bacillus pumilus. J Sichuan University (Nat Sci Ed). 2017:54:1083-8.

47. Shao $H$, Cao Q, Zhao $H$, Tan X, Feng $H$. Construction of novel shuttle expression vectors for gene expression in Bacillus subtilis and Bacillus pumilus. J Gen Appl Microbiol. 2015;61:124-31.

48. Sambrook J, Fritsch EFMT. Molecular cloning: a laboratory manual, 2nd Ed. New York, NY: Cold Spring Harbor; 1989.

49. Meddebmouelhi F, Dulcey C, Beauregard M. High transformation efficiency of Bacillus subtilis with integrative DNA using glycine betaine as osmoprotectant. Anal Biochem. 2012:424:127-9.

50. Wan $M-Y$, Wang $H-Y$, Zhang $Y-Z$, Feng $H$. Substrate specificity and thermostability of the dehairing alkaline protease from Bacillus pumilus. Appl Biochem Biotechnol. 2009;159:394-403.

51. Cheng L-J, Xue Q-H. Laboratory manual of microbiology, 2nd Ed. Beijing: Science Press; 2012

52. Kim D, Langmead B, Salzberg SL. HISAT: a fast spliced aligner with low memory requirements. Nat Methods. 2015;12:357-60.

53. Pertea M, Kim D, Pertea GM, Leek JT, Salzberg SL. Transcript-level expression analysis of RNA-seq experiments with hisat, stringtie and ballgown. Nat Protocols. 2016;11:1650-67.

54. Pertea M, Pertea GM, Antonescu CM, Chang TC, Mendell JT, Salzberg SL. StringTie enables improved reconstruction of a transcriptome from RNA-seq reads. Nat Biotechnol. 2015:33:290-5.

55. Anders S, Pyl PT, Huber W. HTSeq--a Python framework to work with highthroughput sequencing data. Bioinformatics. 2015;31:166-9.

56. Liao Y, Smyth GK, Shi W. featureCounts: an efficient general purpose program for assigning sequence reads to genomic features. Bioinformatics. 2014;30:923-30.

57. Robinson MD, Mccarthy DJ, Smyth GK. edgeR: a Bioconductor package for differential expression analysis of digital gene expression data. Bioinformatics. 2010;26:139-40.

58. Kestler HA, André M, Gress TM, Buchholz M. Generalized venn diagrams: a new method of visualizing complex genetic set relations. Bioinformatics. 2005:21:1592-5.

59. Kanehisa M, Goto S, Sato Y, Kawashima M, Furumichi M, Tanabe M. Data, information, knowledge and principle: back to metabolism in KEGG. Nucleic Acids Res. 2014:42:D199-205.

60. Caraux G, Pinloche S. PermutMatrix: a graphical environment to arrange gene expression profiles in optimal linear order. Bioinformatics. 2005;21: 1280-1.

61. Livak KJ, Schmittgen TD. Analysis of relative gene expression data using real-time quantitative $P C R$ and the $2-\Delta \Delta C T$ method. Methods. 2001;25:402-8.

Ready to submit your research? Choose BMC and benefit from:

- fast, convenient online submission

- thorough peer review by experienced researchers in your field

- rapid publication on acceptance

- support for research data, including large and complex data types

- gold Open Access which fosters wider collaboration and increased citations

- maximum visibility for your research: over $100 \mathrm{M}$ website views per year

At $\mathrm{BMC}$, research is always in progress.

Learn more biomedcentral.com/submission 